\title{
Article \\ Short-Term Intake of Yellowstripe Scad versus Salmon Did Not Induce Similar Effects on Lipid Profile and Inflammatory Markers among Healthy Overweight Adults despite Their Comparable EPA+DHA Content
}

\author{
Wei Lin Chang ${ }^{1}\left(\mathbb{D}\right.$, Azrina Azlan ${ }^{1} \mathbb{D}$, Sabariah Md Noor ${ }^{2} \mathbb{D}$, Irmi Zarina Ismail ${ }^{3} \mathbb{D}$ and Su Peng Loh ${ }^{1,4, * \mathbb{D}}$ \\ 1 Department of Nutrition, Faculty of Medicine and Health Sciences, Universiti Putra Malaysia, \\ Serdang 43400, Selangor, Malaysia; chang.weilin@outlook.com (W.L.C.); azrinaaz@upm.edu.my (A.A.) \\ 2 Department of Pathology, Faculty of Medicine and Health Sciences, Universiti Putra Malaysia, \\ Serdang 43400, Selangor, Malaysia; md_sabariah@upm.edu.my \\ 3 Department of Family Medicine, Faculty of Medicine and Health Sciences, Universiti Putra Malaysia, \\ Serdang 43400, Selangor, Malaysia; irmiismail@upm.edu.my \\ 4 Department of Nutrition, Faculty of Public Health, Universitas Airlangga, Jl. Mulyorejo Kampus C, \\ Surabaya 60115, Indonesia \\ * Correspondence: sploh@upm.edu.my; Tel.: +60-3-9769-2432
}

\section{check for}

updates

Citation: Chang, W.L.; Azlan, A.; Noor, S.M.; Ismail, I.Z.; Loh, S.P. Short-Term Intake of Yellowstripe Scad versus Salmon Did Not Induce Similar Effects on Lipid Profile and Inflammatory Markers among Healthy Overweight Adults despite Their Comparable EPA+DHA Content. Nutrients 2021, 13, 3524. https://doi.org/10.3390/nu13103524

Academic Editor: Yan Chen

Received: 8 September 2021

Accepted: 4 October 2021

Published: 8 October 2021

Publisher's Note: MDPI stays neutral with regard to jurisdictional claims in published maps and institutional affiliations.

Copyright: (c) 2021 by the authors. Licensee MDPI, Basel, Switzerland. This article is an open access article distributed under the terms and conditions of the Creative Commons Attribution (CC BY) license (https:// creativecommons.org/licenses/by/ $4.0 /)$.
Abstract: Yellowstripe scad (YSS) have comparable eicosapentaenoic acid and docosahexaenoic acid (EPA+DHA) content to salmon. We aimed to compare the effects of YSS and salmon on lipid profile and inflammatory markers. A randomized crossover trial with two diet periods was conducted among healthy overweight (with BMI 23.0-27.4 kg/m²) Malaysian adults aged 21-55 years. Steamed whole YSS fish $(\approx 385 \mathrm{~g}$ whole fish/day) or salmon fillets $(\approx 246 \mathrm{~g}$ fillet/day) were given for eight weeks (3 days per week), retaining approximately $1000 \mathrm{mg}$ EPA+DHA per day. Diets were switched after an 8-week washout period. Fasting blood samples were collected before and after each diet period. A total of 49 subjects participated in the intervention (35\% male and $65 \%$ female; mean age 29 (7) years). YSS did not induce any significant changes in outcome measures. However, the consumption of salmon as compared with YSS was associated with reduction in triglycerides (between-group difference: $-0.09 \mathrm{mmol} / 1, p=0.01$ ), VLDL-cholesterol (between-group difference: $-0.04 \mathrm{mmol} / 1, p=0.01$ ), atherogenic index of plasma (between-group difference: $-0.05 \mathrm{mmol} / 1$, $p=0.006$ ), and IL-6 (between-group difference: $-0.01 \mathrm{pg} / \mathrm{mL}, p=0.03$ ). Despite their comparable $\mathrm{EPA}+\mathrm{DHA}$ content, short-term consumption of salmon but not YSS induced significant changes in lipid profile and inflammatory markers. Larger clinical trials are needed to confirm the findings.

Keywords: dietary fish; yellowstripe scad; salmon; omega-3 fatty acids; eicosapentaenoic acid; docosahexaenoic acid; lipid profile; inflammatory markers; randomized crossover trial

\section{Introduction}

Malaysia is among the world's biggest consumers of fish, eating at least $56.5 \mathrm{~kg}$ of fish per person each year [1]. More than three quarters of Malaysians consume fish at least twice per week, eating $168 \mathrm{~g}$ of fish per day [2]. Eating fish on a regular basis can be beneficial for our health in many ways. For example, fish could help to reduce the risk of cardiovascular disease (CVD) and improve the chances of survival following a heart attack, as displayed in several observational studies [3-5], although not all agree [6]. Researchers believe that the heart health benefit of fish is more promising in those fish rich in omega- 3 fatty acids, which is attributed to the ability of fish to ameliorate hypertriglyceridemia $[7,8]$ and resolve inflammatory processes [9]. A recent meta-analysis demonstrated that consuming oily fish was associated with significant reductions in plasma triglycerides and an increase in HDL-cholesterol [10]. Omega-3 fatty acids reduce plasma lipid levels by inhibiting 
triacylglycerol and VLDL synthesis in liver, increasing fatty acid oxidation, as well as promoting the synthesis of membrane phospholipids [11-13]. Increased dietary EPA intake appears to compete with arachidonic acid (AA, omega- 6 fatty acids) for the same desaturation enzymes, and in turn produces eicosanoids that are less potent than those produced from AA [14]. Pro-resolving mediators such as resolvins and protectins derived from EPA and DHA also helps in regulating the inflammatory response [9]. Omega-3 fatty acids are essential polyunsaturated fatty acids that must obtain from diet due to the lack of delta-12 and delta-15 desaturases in humans [15]. Eicosapentaenoic acid (EPA) and docosahexaenoic acid (DHA) are the two main long-chain omega-3 fatty acids commonly found in marine sources [16]. Marine fish, especially salmon, are the principal source of EPA and DHA [17]. In Malaysia, people consume mostly farmed Atlantic salmon, particularly Norwegian salmon [18]. However, salmon can be costly and require importation for tropical countries such as Malaysia. Yellowstripe scad (YSS, ikan selar kuning) is one of the most frequently consumed local fish in Malaysia [2]. Many Asian populations like to consume it as snack in the form of dried fish while Malaysians usually deep-fry and serve it with nasi lemak. It is not only commonly available in Malaysia but also affordable in price. Recent studies showed that YSS could provide a comparable eicosapentaenoic acid and docosahexaenoic acid (EPA+DHA) content to farmed Atlantic salmon $(879 \mathrm{mg} / 100 \mathrm{~g}$ vs. $947 \mathrm{mg} / 100 \mathrm{~g})[19,20]$. However, studies exploring the benefits of YSS are scarce. The current study previously demonstrated an alteration of leptin and prothrombotic parameter upon the consumption of YSS and salmon [21]. In this paper, we aimed to investigate the effects of consuming YSS as compared with salmon on lipid profile and inflammatory markers among healthy overweight subjects.

\section{Materials and Methods}

\subsection{Study Design and Subjects}

A randomized, two-period crossover trial was carried out under free-living conditions among staff and students in Universiti Putra Malaysia (UPM) from October 2016 to May 2017. The Ethics Committee Research Involving Human Respondents of Universiti Putra Malaysia (JKEUPM) approved the study protocol. The trial was registered under the National Medical Research Register (NMRR-16-2693-3230) and ClinicalTrials.gov (NCT03251014). The subjects were healthy Malaysian adults aged 21-55 years and were overweight (BMI 23.0-27.4 kg/m²) according to the Asian BMI cut-offs [22]. Subjects were excluded if they reported (i) having cardiovascular disease, haemostasis disorder (haemophilia or thrombosis-related disorders), inflammatory disease, diabetes mellitus, hypertension $(>140 / 90 \mathrm{~mm} \mathrm{Hg}$ ), or other significant medical history that could prohibit the participation; (ii) receiving warfarin/aspirin treatment, or medication to lower blood lipids, blood pressure, and inflammation; (iii) menopause, pregnancy, or lactating; (iv) consuming fish twice or more per week, or taking fish oil supplements for the last one month.

\subsection{Diet}

The intervention diets were steamed whole YSS $(\approx 385 \mathrm{~g}$ whole fish/day, which corresponded to $\approx 265 \mathrm{~g}$ fillet/day) and farmed Atlantic salmon fillet ( $\approx 246 \mathrm{~g}$ fillet/day). Whole YSS was provided because it is too small in size, making it impractical to be filleted. An experiment on determining the net weight of YSS fillet was conducted by measuring the initial weight (whole fish) and final weight (fillet) of YSS after removing the head, bones, and tail. Based on the result, an additional weight of $45.1 \%(30.7 \pm 6.6 \mathrm{~g})$ was taken into account when portioning whole YSS (total weight of $385 \mathrm{~g} /$ day). The amount of fish given was based on the EPA+DHA intake for greatest cardioprotection $(1000 \mathrm{mg} /$ day or $7000 \mathrm{mg} /$ week) [23], as shown in Table 1. Subjects were required to consume the fish three times (days) per week during weekdays [24]. 
Table 1. Amount of fish given.

\begin{tabular}{|c|c|c|c|}
\hline Diet & Amount Given & Frequency & $\begin{array}{l}\text { Corresponding EPA+DHA } \\
\text { Content * }\end{array}$ \\
\hline Steamed YSS & $\approx 385 \mathrm{~g}$ whole fish/day ** & 3 times (days)/week & $2329 \mathrm{mg} /$ day ( $\approx 7000 \mathrm{mg} /$ week $)$ \\
\hline Steamed salmon & $\approx 246 \mathrm{~g}$ fillet/day & 3 times (days)/week & $2330 \mathrm{mg} /$ day ( $\approx 7000 \mathrm{mg} /$ week $)$ \\
\hline
\end{tabular}

The fish was steamed in aluminium foil based on the method adopted from Koubaa et al. [25] with slight modification. The fish was seasoned with either salt or white pepper and covered with other ingredients (such as garlic, onion, ginger, chilies, and lemongrass) and sauces (such as soy sauce, oyster sauce, black pepper sauce, and so on). Water in the steamer was brought to boil before cooking the fish with the lid on for $20 \mathrm{~min}$. Steaming was selected as the cooking method as it retains the most EPA and DHA content as compared with other cooking methods (baking in foil, frying, and grilling) [26].

\subsection{Intervention}

A randomized, two-period crossover trial was carried out under free-living conditions. All the subjects were randomly assigned to either the first or second group. A tamper-proof block randomization procedure was followed to ensure an equal allocation ratio. The random allocation sequence was created using computer-generated random numbers. Unlike other types of treatment such as diet pills, the diet treatment of this study could not be matched in taste, texture, and appearance, thus making the blinding of researchers and subjects impossible. To acknowledge the potential bias from a lack of blinding, precautions were made by ensuring both allocation groups were treated as equally as possible through the standardization of co-intervention, frequency of follow-up, and care of subjects [27].

The first group of subjects received YSS followed by salmon, while the second group received salmon followed by YSS. The diets were administered in the form of a lunchbox containing the steamed fish dishes served with one serving of cooked white rice (1 cup, cooked) and vegetable side dish ( $\frac{1}{2}$ cup, cooked) [28]. All the foods were the same across the groups except for the types of fish. Subjects were instructed to consume one lunchbox in a day for three days per week. The same type of cooked fish was given for eight weeks, with a washout period of 8 weeks between the two interventions [29]. Throughout the intervention period, subjects were instructed to refrain from consuming omega-3 rich food entirely but otherwise to make no changes in their diets. A list of commonly consumed omega-3 rich food was provided to the subjects (Table 2). This is to minimize the bias toward overestimating the intervention effect [30]. Subjects were required to snap a photo of the lunchbox (including possible leftovers) after their meal to monitor their compliance to the diet given [31]. The compliance index was calculated based on the following formula [32]:

$$
\text { Compliance index }(\%)=\frac{\text { Total number of treatment (lunchbox) consumed }}{\text { Total number of treatment (lunchbox) theorectically required }} \times 100
$$

Good compliance is defined as no more than a 10\% deviation from absolute adherence [32]. All the subjects achieved at least $90 \%$ of the compliance index. 
Table 2. List of omega-3 rich food.

\begin{tabular}{cc}
\hline Food Group & Food \\
\hline & Salmon \\
& Yellowstripe scad \\
Fish and seafood & Mackerel \\
& Sardine \\
& Tuna \\
& Trout \\
& Herring \\
Meat, eggs and poultry & Threadfin bream \\
Dairy products & Anchovies \\
& Omega-3 enriched eggs \\
Nuts and seeds & Omega-3 enriched milk \\
& Flaxseeds/linseeds \\
& Chia seeds \\
Fats and oils & Walnuts \\
& Cod liver oil \\
& Flaxseed oil \\
\end{tabular}

\subsection{Outcome Measures}

Body weight and height were assessed before and after each diet period. The compliance with dietary intake and physical activity was monitored through self-administered two-day 24-h dietary recall (24HR) [33] and International Physical Activity Questionnaires (IPAQ) [34], respectively. A fasting blood sample $(7 \mathrm{~mL})$ was taken to determine the serum EPA+DHA level, blood lipid profile, and inflammatory markers.

The serum EPA+DHA level was performed based on the modified method described elsewhere $[35,36]$. The samples were methylated using boron trifluoride (BF3)/methanol and analysed by gas chromatography. Gas chromatographic analysis was performed on an Agilent 6890 gas chromatograph equipped with flame ionization detectors, and a capillary column (DB-23, $0.25 \mathrm{~mm} \times 60 \mathrm{~m}, 0.15 \mu \mathrm{m}$ film, J \& W Scientific) [37]. Fatty acid methyl esters were identified by comparing the retention times to those of known standards. Methyl heptadecanoate (C17:0) was used as an internal standard.

The lipid profile was analysed by a medical diagnostic laboratory (Clinipath Malaysia Sdn Bhd, Selangor, Malaysia). In the medical diagnostic laboratory, the analysis of total cholesterol and triglycerides was performed on a fully automatic biochemistry analyzer (COBAS 6000 analyzer, Roche Diagnostics, Mannheim, Germany). Serum HDL-cholesterol was determined calorimetrically using the HDL separation tab (Union Carbide Corporation, Pleasantville, NY, USA). VLDL-cholesterol was estimated by dividing triglyceride level with a factor of 2.2, whereas LDL-cholesterol was calculated using the Friedewald formula [38]:

LDL-cholesterol (mmol/1)

$=$ Total cholesterol $(\mathrm{mmol} / 1)-$ HDL-cholesterol $(\mathrm{mmol} / 1)-$ VLDL-cholesterol (mmol/1),

where by VLDL-C $(\mathrm{mmol} / 1)=\mathrm{TG}(\mathrm{mmol} / 1) / 2.2$.

The atherogenic coefficient (non-HDL-cholesterol/HDL-cholesterol) was determined, whereby non-HDL cholesterol was calculated by subtracting the HDL-cholesterol value from the total cholesterol. The atherogenic index of plasma (AIP) was calculated as $\log _{10}$ (TG/HDL-C) [39].

Inflammatory markers, including IL-1 $\beta$, IL-6, TNF- $\alpha$, and IFN- $\alpha$, were determined using a custom Magnetic Luminex human premixed multi-analyte kit (R\&D Systems, Minneapolis, MN, USA). As stated by the manufacturer, the detection limits for IL-1 $\beta$, IL-6, TNF- $\alpha$, and IFN- $\alpha$ were $0.11 \mathrm{pg} / \mathrm{mL}, 0.10 \mathrm{pg} / \mathrm{mL}, 0.10 \mathrm{pg} / \mathrm{mL}$, and $0.09 \mathrm{pg} / \mathrm{mL}$; whereas sensitivities of the assay were $0.27 \mathrm{pg} / \mathrm{mL}, 0.36 \mathrm{pg} / \mathrm{mL}, 0.60 \mathrm{pg} / \mathrm{mL}$, and $0.31 \mathrm{pg} / \mathrm{mL}$. 


\subsection{Statistical Analysis}

The analyses presented were among the prespecified secondary outcomes of the present study, while thrombosis as the primary outcome was the basis for the sample size calculation [21]. The sample size was calculated using the two-sided comparison of means in a repeated measures design [40]. It was determined by designing the trial to have $90 \%$ power and an $\alpha$ of 0.05 to detect a significant difference. A power calculation was performed based on the documented difference of $2.32 \%$ in plasma plasminogen activator inhibitor-1 upon DHA supplementation [41]. An effect size of 0.6925 [41] and an assumed attrition rate of $20 \%$ indicated a minimum sample size of 48 subjects per group.

All data obtained were analyzed using IBM SPSS Statistics version 23 (IBM Corp, Armonk, NY, USA). Exploratory data analysis was initially carried out to check for the normality of data. Any skewed variables were normalized by natural log transformation. If the variables remained skew after data transformation, non-parametric tests were applied. Analyses followed the intention-to-treat principle, categorizing participants according to the randomized assignment of treatment regardless of compliance. The differences between baseline and end values for each diet group were tested using paired samples $t$-test for parametric data and Wilcoxon signed-rank test for non-parametric data. Two-way repeated measures analysis of variance (ANOVA) with baseline values as a covariate was used to determine the differences between YSS and salmon [42]. All $p$-values $<0.05$ were regarded as significant.

\section{Results}

Of the 98 subjects screened, 50 subjects were recruited in the study. There was an $8 \%$ dropout rate due to the difficulty of following the diet $(n=3)$ and personal reasons $(n=1)$. One menopausal subject was retrospectively excluded because she was mistakenly randomized into the study but did not receive any intervention. The exclusion of data under this circumstance did not affect the results [43]. The final analysis included 49 subjects based on the intention-to-treat principle. Figure 1 outlines the flow of participants over the 24-week study period based on CONSORT 2010 statement. The sociodemographic characteristics of the subjects are summarized in Table 3.

During the intervention, three samples of respective cooked fish were randomly selected to analyse for their fatty acid content via gas chromatography analysis by an established medical diagnostic laboratory (Unipeq Sdn Bhd, Selangor, Malaysia). The fatty acid composition of fish is presented in Table 4. The comparison of EPA and DHA content between YSS and salmon is further discussed in Section 3.4.

Table 3. Socio-demographic characteristics of subjects $(n=49)$.

\begin{tabular}{ccc}
\hline Socio-Demographic Characteristics & $\boldsymbol{n}$ & \% \\
\hline Age (years) & \multicolumn{2}{c}{29} \\
Mean & \multicolumn{2}{c}{7} \\
SD & \multicolumn{2}{c}{$21-46$} \\
Range & \multicolumn{2}{c}{34.7} \\
Sex & 17 & 65.3 \\
Male & 32 & \\
Female & & \\
Ethnicity & 35 & 71.4 \\
Malay & 12 & 24.5 \\
Chinese & 2 & 4.1 \\
Indian & \multicolumn{2}{c}{. }
\end{tabular}




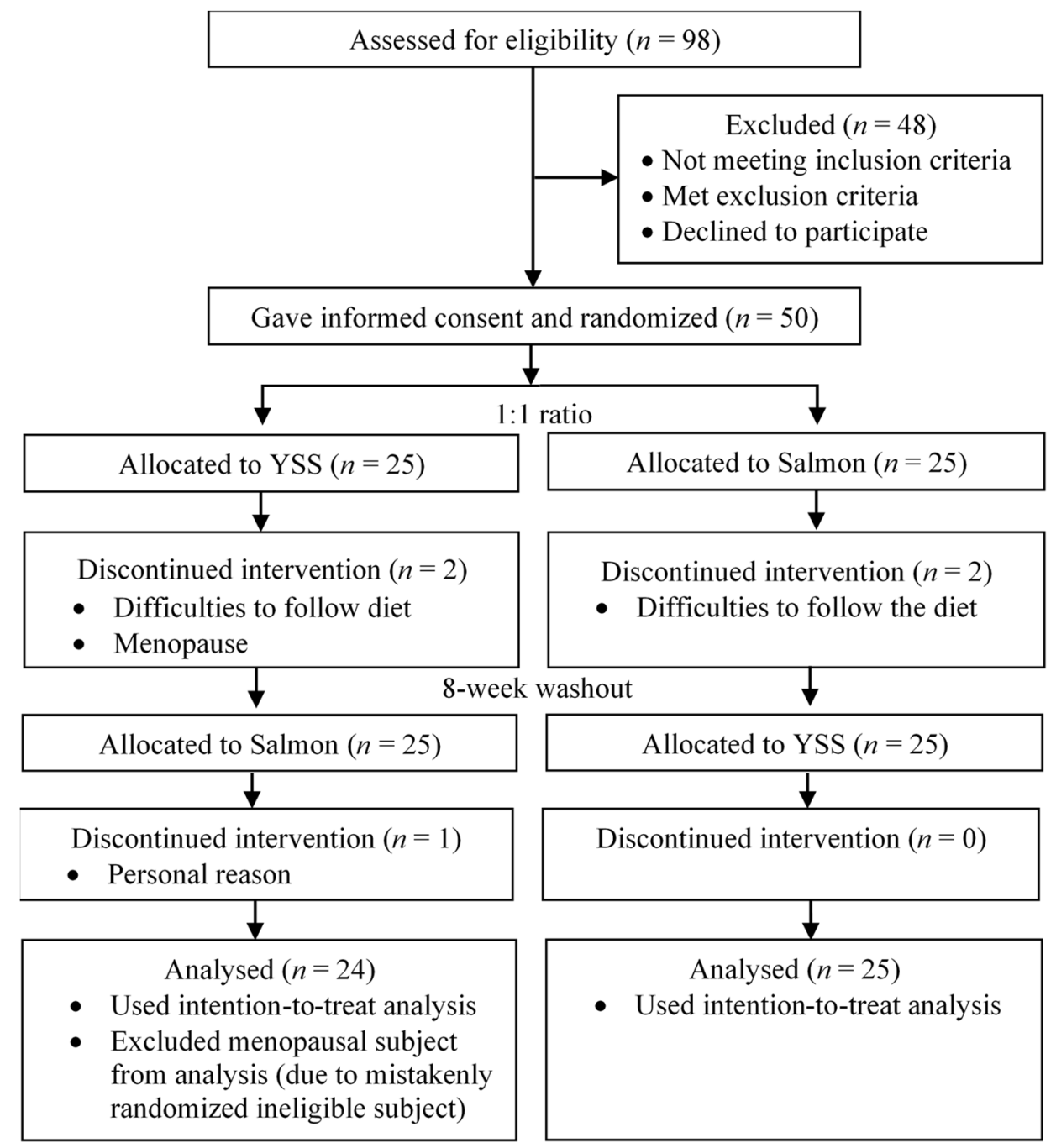

Figure 1. CONSORT subject flow diagram over the 24-week study period.

Table 4. Fatty acid composition of fish.

\begin{tabular}{ccc}
\hline Fatty Acid Composition & YSS & Salmon \\
\hline Total fat (g/100g) & 3.33 & 15.17 \\
Saturated fat (mg/100 g sample) & 1751.64 & 2557.48 \\
Caprylic acid 8:0 & 1.61 & 0.66 \\
Capric acid 10:0 & 0.00 & 2.38 \\
Undecanoic acid 11:0 & 0.76 & 0.24 \\
Lauric acid 12:0 & 26.29 & 169.65 \\
Tridecanoic acid 13:0 & 2.46 & 1.96 \\
Myristic acid 14:0 & 246.37 & 334.74 \\
Pentadecanoic acid 15:0 & 58.94 & 30.36 \\
Palmitic acid 16:0 & 895.24 & 1462.68 \\
Heptadecanoic acid 17:0 & 25.97 & 35.65 \\
Stearic acid 18:0 & 375.17 & 405.72 \\
Arachidic acid 20:0 & 24.45 & 53.39 \\
Henicosanoic acid 21:0 & 7.32 & 4.44 \\
Behenic acid 22:0 & 21.26 & 27.80 \\
\hline
\end{tabular}


Table 4. Cont.

\begin{tabular}{ccc}
\hline Fatty Acid Composition & YSS & Salmon \\
\hline Tricosanoic acid 23:0 & 55.26 & 19.84 \\
Lignoceric acid 24:0 & 10.58 & 7.98 \\
Monounsaturated fat (mg/100 g sample) & 561.46 & 8017.96 \\
Myristoleic acid 14:1 & 1.42 & 6.05 \\
Cis-10-pentadecenoic acid 15:1 & 0.13 & 3.42 \\
Palmitoleic acid 16:1 & 254.24 & 374.85 \\
Cis-10-heptadecanoic acid 17:1 & 63.41 & 32.69 \\
Elaidic acid 18:1n9t & 3.60 & 0.00 \\
Oleic acid 18:1n9c & 210.96 & 6870.41 \\
Cis-11-eicosenoic acid 20:1n9 & 5.48 & 324.02 \\
Erucic acid 22:1n9 & 4.21 & 350.91 \\
Nervonic acid 24:1 & 18.02 & 55.61 \\
Linolelaidic acid 18:2n6t & 1020.83 & 4593.94 \\
Linoleic acid 18:2n6c & 0.00 & 17.04 \\
P-Linolenic acid 18:3n6 & 73.65 & 2274.80 \\
$\alpha$-Linolenic acid 18:3n3 & 13.19 & 40.29 \\
Cis-11,14-eicosadienoic acid 20:2n6 & 28.52 & 894.95 \\
Cis-8,11,14-eicosatrienoic acid 20:3n6 & 14.54 & 173.17 \\
Cis-11,14,17-eicosatrienoic acid 20:3n3 & 7.57 & 48.79 \\
Arachidonic acid 20:4n6 & 99.92 & 40.15 \\
Cis-5,8,11,14,17-eicosapentaenoic acid 20:5n3 & 3.49 & 74.86 \\
Docosadienoic acid 22:2 & 214.16 & 400.52 \\
Cis-4,7,10,13,16,19-docosahexaenoic acid 22:6n3 & 10.16 & 18.75 \\
\hline & 555.66 & 610.63 \\
\hline
\end{tabular}

Table 5 presents the changes in dietary intake, physical activity, serum EPA+DHA level, blood lipid profile, and inflammatory profile of subjects after 8-week consumption of YSS as compared with salmon. The baseline values of all the measured variables were comparable between two diet groups, indicating the absence of carry-over effects. The energy intake, macronutrient intake, and physical activity level of subjects in both groups remained unchanged throughout the intervention. The body mass index was unlikely to be different from baseline and across diet groups. The observed changes confirmed a good compliance of subjects to the study instructions. 
Table 5. Changes in dietary intake, physical activity, serum EPA+DHA level, blood lipid profile, and inflammatory profile of subjects after intervention $(n=49)$.

\begin{tabular}{|c|c|c|c|c|c|c|c|c|c|}
\hline & \multicolumn{3}{|c|}{ YSS } & \multicolumn{3}{|c|}{ Salmon } & \multirow{2}{*}{$\begin{array}{l}\text { Between-Group } \\
\text { Difference }^{2}\end{array}$} & \multirow{2}{*}{$95 \% \mathrm{CI}$} & \multirow{2}{*}{$p$ Value ** } \\
\hline & Baseline $^{1}$ & Week 8 & $p$ Value * & Baseline $^{1}$ & Week 8 & $p$ Value * & & & \\
\hline \multicolumn{10}{|l|}{ Dietary intake } \\
\hline Energy (kcal/day) & $1359(368)$ & $1448(487)$ & 0.16 & $1356(357)$ & $1413(548)$ & 0.44 & 32.00 & $-135 ; 206$ & 0.06 \\
\hline Protein (g/day) & $173.78(52.23)$ & $181.01(68.33)$ & 0.42 & $173.47(45.44)$ & $180.08(65.52)$ & 0.44 & 0.62 & $-19.78 ; 21.63$ & 0.10 \\
\hline Total Fat (g/day) & $47.61(18.75)$ & $50.28(26.37)$ & 0.31 & 47.53 (17.73) & $49.93(25.82)$ & 0.49 & 0.27 & $-7.59 ; 8.30$ & 0.10 \\
\hline PUFA 20:5, EPA (g/day $)^{3}$ & $0.01(0.04)$ & $0.00(0.02)$ & $0.34^{\S}$ & $0.01(0.03)$ & $0.03(0.15)$ & $0.002 \S$ & -0.03 & $0.00 ; 0.05$ & $0.01^{+}$ \\
\hline PUFA 22:6, DHA (g/day) ${ }^{3}$ & $0.04(0.11)$ & $0.04(0.11)$ & $0.74 \S$ & $0.03(0.06)$ & $0.06(0.20)$ & $0.002 \S$ & -0.03 & $0.01 ; 0.15$ & $0.24^{+}$ \\
\hline Saturated fat (g/day) & $13.66(6.84)$ & $11.34(6.51)$ & 0.66 & $14.76(10.56)$ & $13.40(10.87)$ & 0.37 & -0.96 & $1.55 ; 5.67$ & 0.71 \\
\hline Body mass index $\left(\mathrm{kg} / \mathrm{m}^{2}\right)$ & $25.20(1.57)$ & $25.14(1.69)$ & 0.25 & $25.29(1.59)$ & $25.27(1.66)$ & 0.78 & -0.040 & $-0.28 ; 0.03$ & 0.48 \\
\hline Serum EPA+DHA (ug/mL) & $94.31(150.56)$ & $100.46(90.34)$ & 0.81 & $98.21(78.99)$ & $123.97(116.48)$ & 0.11 & -19.61 & $-45.95 ; 14.04$ & 0.29 \\
\hline Serum EPA & $3.80(16.02)$ & $2.05(10.06)$ & 0.43 & $4.47(13.75)$ & $13.75(26.62)$ & 0.04 & -11.03 & $-8.63 ; 1.10$ & 0.13 \\
\hline Serum DHA & $90.51(150.07)$ & $98.41(89.65)$ & 0.76 & $93.73(78.91)$ & $110.22(114.85)$ & 0.32 & -8.59 & $-41.73 ; 17.34$ & 0.41 \\
\hline \multicolumn{10}{|l|}{ Blood lipid profile } \\
\hline Total cholesterol $(\mathrm{mmol} / 1)$ & $5.18(0.83)$ & $5.19(0.97)$ & 0.71 & $5.12(0.15)$ & $5.24(0.89)$ & 0.14 & -0.11 & $-0.24 ; 0.12$ & 0.92 \\
\hline Triglycerides $(\mathrm{mmol} / 1)$ & $1.11(0.52)$ & $1.04(0.47)$ & 0.38 & $1.06(0.49)$ & $0.90(0.38)$ & $<0.001$ & 0.09 & $0.06 ; 0.22$ & 0.01 \\
\hline HDL-cholesterol (mmol/1) & $1.56(0.27)$ & $1.55(0.30)$ & 0.88 & $1.56(0.37)$ & $1.62(0.29)$ & 0.008 & -0.07 & $-0.13 ;-0.01$ & 0.41 \\
\hline LDL-cholesterol (mmol/1) & $3.12(0.77)$ & $3.11(0.85)$ & 0.86 & $3.08(0.88)$ & $3.19(0.82)$ & 0.13 & -0.12 & $-0.23 ; 0.08$ & 0.20 \\
\hline VLDL-cholesterol $(\mathrm{mmol} / 1)$ & $0.51(0.23)$ & $0.48(0.22)$ & 0.55 & $0.48(0.22)$ & $0.41(0.17)$ & $<0.001$ & 0.04 & $0.03 ; 0.11$ & 0.01 \\
\hline \multicolumn{10}{|l|}{ Inflammatory markers $(\mathrm{pg} / \mathrm{mL})^{4}$} \\
\hline IL-1 $\beta$ & $1.17(0.16)$ & $1.14(0.16)$ & 0.77 & $1.13(0.15)$ & $1.13(0.16)$ & 0.19 & -0.03 & $-0.02 ; 0.05$ & 0.97 \\
\hline IL-6 & $0.69(0.21)$ & $0.66(0.21)$ & 0.43 & $0.68(0.18)$ & $0.64(0.20)$ & 0.03 & 0.01 & $-0.04 ; 0.07$ & 0.03 \\
\hline TNF- $\alpha$ & $1.38(0.19)$ & $1.36(0.21)$ & 0.19 & $1.37(0.21)$ & $1.34(0.21)$ & 0.007 & 0.01 & $-0.01 ; 0.04$ & 0.95 \\
\hline IFN- $\gamma$ & $2.15(0.36)$ & $2.12(0.36)$ & 0.91 & $2.10(0.33)$ & $2.11(0.35)$ & 0.43 & -0.04 & $-0.03 ; 0.05$ & 0.25 \\
\hline
\end{tabular}

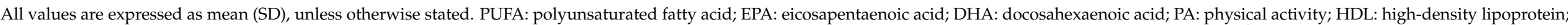

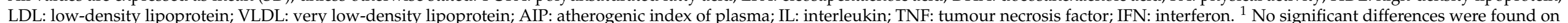

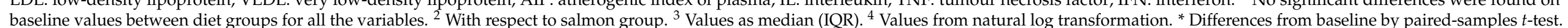

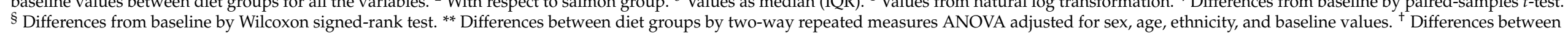
diet groups by Friedman ANOVA by ranks. 
Only the salmon group demonstrated a threefold increase in EPA intake $(p=0.002)$ and twofold increase in DHA intake $(p=0.002)$. Pairwise comparison using Friedman's tests revealed that the between-group difference was significant on EPA intake (median difference of $-0.03 \mathrm{~g} / \mathrm{day}, p=0.01$ ), but not on DHA intake (median difference of $-0.03 \mathrm{~g} /$ day, $p=0.24)$.

\subsection{Serum EPA+DHA Level}

There were no changes in serum EPA+DHA levels after the consumption of YSS and salmon (Table 5). When the omega-3 fatty acids were assessed individually, although salmon increased the serum EPA twofold $(p=0.04)$ at 8 weeks, the between-group difference was not significant. No significant changes were found on serum DHA with both diets.

\subsection{Blood Lipid Profile}

YSS did not induce significant changes to the blood lipid profile. Conversely, salmon significantly reduced triglycerides by $15.1 \%$ (between-group difference: $-0.09 \mathrm{mmol} / 1$, $p=0.01$ ),VLDL-cholesterol by $14.6 \%$ (between-group difference: $-0.04 \mathrm{mmol} / 1, p=0.01$ ), and AIP by $0.4 \%$ (between-group difference: $-0.05 \mathrm{mmol} / 1, p=0.006$ ) as compared with YSS. The results suggest that the effect of salmon on reducing triglycerides, VLDLcholesterol, and AIP was significantly stronger than YSS. HDL-cholesterol increased after the consumption of salmon (within-group difference: $+3.9 \%, p=0.008$ ), with no significant difference between the two diets (Table 5).

\subsection{Inflammatory Markers}

YSS did not induce changes on the inflammatory markers IL-1 $\beta$, IL-6, TNF- $\alpha$, and IFN- $\gamma$ at 8 weeks (Table 5). On the contrary, there was a significant reduction in IL-6 and TNF- $\alpha$ from baseline with salmon (within-group difference: $-5.9 \%$ and $-2.2 \%, p=0.03$ and $<0.001$ ). However, significant relative change between salmon as compared with YSS was only observed on IL-6 (between-group difference of $\log$ (IL-6): $-0.01 \mathrm{pg} / \mathrm{ml}, p=0.03$ ) but not TNF- $\alpha$. Other inflammatory markers did not change significantly with salmon at 8 weeks.

\subsection{EPA+DHA Content of Fish}

As shown in Table 6, the mean EPA+DHA contents of YSS and salmon were $769.82 \pm 80.48 \mathrm{mg} / 100 \mathrm{~g}$ sample and $1011.16 \pm 94.40 \mathrm{mg} / 100 \mathrm{~g}$ sample, respectively. The current findings were comparable with those reported in the previous study $[19,20]$. Although the EPA+DHA content of YSS was lower than salmon, the difference was not significant. When EPA and DHA were assessed individually, YSS had significantly lower EPA content as compared with salmon (between-group difference: $-0.03 \mathrm{~g} /$ day, $p=0.01$ ), whereas the DHA content was similar between YSS and salmon.

Table 6. EPA+DHA content of YSS as compared with salmon $(n=3)$.

\begin{tabular}{cccccc}
\hline $\begin{array}{c}\text { Nutrient Content } \\
\text { (mg/100 g Sample) }\end{array}$ & YSS & Salmon & $\begin{array}{c}\text { Between-Group } \\
\text { Difference } \$\end{array}$ & $\mathbf{9 5 \%}$ CI & $p$ Value \\
\hline Total EPA+DHA & $769.82(80.48)$ & $1011.16(94.40)$ & -241.35 & $-627.95 ; 145.26$ & 0.11 \\
EPA & $214.16(22.77)$ & $400.53(17.32)$ & -186.37 & $-273.40 ;-99.33$ & 0.01 \\
DHA & $555.66(57.71)$ & $610.64(77.08)$ & -54.98 & $-347.93 ; 237.97$ & 0.50 \\
\hline
\end{tabular}

All values are expressed as mean (SD). EPA: eicosapentaenoic acid; DHA: docosahexaenoic acid. ${ }^{\S}$ With respect to salmon group.

\section{Discussion}

The present study investigated the effect of YSS as compared with salmon on the lipid profile and inflammatory markers among healthy overweight subjects. A crossover design was selected for several reasons. Firstly, the intervention is evaluated within the same participants, thus eliminating the between-subject variability [44]. Secondly, this study design is more sensitive than parallel-group design to detect small differences between 
equivalent treatments such as YSS and salmon that have similar EPA+DHA content [45]. Thirdly, since each participant serves as his or her own control, fewer subjects are required to achieve a similar statistical power [46]. The 8-week duration of the diet period was chosen as this time frame was sufficient to incorporate EPA+DHA into tissues [47] and to induce notable effects in the lipid profile [8] and inflammation [48]. A washout period of 8 weeks allowed to reduce the possible carry-over effect from the crossover study design, as indicated by the insignificant changes between the baseline values of YSS and salmon.

The consumption of YSS did not induce significant benefits on the lipid profile. Instead, salmon improved triglycerides and VLDL-cholesterol levels. Published interventional data displaying the lipid-lowering effects of dietary fish are conflicting. A crossover trial by Lindqvist et al. [49] documented that the triglyceride-lowering effect by 6-week consumption of herring fish (equivalent to $1200 \mathrm{mg}$ EPA+DHA/day) was no difference from pork and chicken fillets (equivalent to $400 \mathrm{mg}$ EPA+DHA/day). The author concluded that total dietary composition (protein, carbohydrates, and fat) rather than increased fish intake plays a crucial role in improving the triglyceride level. Unfortunately, a later study did not support this hypothesis [8]. The 8-week, parallel-arm, randomized intervention study demonstrated a dose-dependent relationship between the triglyceride-lowering effect of fatty fish diets and their EPA+DHA intake, suggesting that dietary EPA+DHA intake played a higher role than total dietary composition [8]. In contrast, the current results reported a significant triglyceride-lowering effect by salmon compared with YSS, although both dietary fish had similar EPA+DHA content. With that, whether total dietary composition or high omega-3 fish diet contribute to the lowering effect on triglycerides is far less certain.

The atherogenic index of plasma (AIP) is the most sensitive marker for predicting cardiovascular risk compared with other atherogenic indices, including atherogenic coefficient [50]. AIP values increase with the cardiovascular risk [39]. In this study, AIP reduced significantly after the consumption of salmon as compared with YSS, indicating that salmon is superior in improving the lipid profile and the occurrence of cardiovascular events. Derosa et al. [51] found an increase in HDL-cholesterol and decreased triglycerides after 18 months of omega-3 supplementation. Although consuming fresh fish seems to provide more promising benefits in AIP than omega-3 supplement [52], research exploring the effect dietary fish on AIP is still scarce. Devadawson et al. [53] showed a statistical difference between inland fish and sea fish eaters on the AIP level; however, which group of fish eaters had a better profile was not stated clearly.

Moreover, HDL-cholesterol was significantly increased by $3.9 \%$ or $0.06 \mathrm{mmol} / 1$ from baseline with the consumption of salmon. According to Gordon et al. [54], each increase in baseline HDL-cholesterol of $0.03 \mathrm{mmol} / 1$ is associated with a $6 \%$ decrease in the risk of death from CVD. In this case, the improvement of salmon on HDL-cholesterol presented in the current study would be unequivocally of great benefit to the population. Previously, LDL-cholesterol was significantly reduced following 8-week consumption of Namibia hake, a type of white fish rich in omega-3 fatty acids (equivalent to $642 \mathrm{mg}$ EPA+DHA/day) [55]. The current study findings, however, are not in line with the previous evidence. Being also a type of white fish rich in omega-3 fatty acid, the consumption of YSS (equivalent to $1000 \mathrm{mg}$ EPA+DHA/day) did not exert significant effect LDL-cholesterol. The study by Vazquez et al. [55] explained that the observed reduction in serum LDL-cholesterol may not be a direct effect of omega-3 fatty acid content in fish; instead, a reduced intake of saturated fats from other protein sources may lead to lower LDL-cholesterol among subjects during the period of fish intake. These results are in keeping with the hypothesis from the previous study that reduced saturated fat intake rather than omega- 3 content of fish contributed to a lower level of LDL-cholesterol. Future trials are warranted to confirm this hypothesis.

Despite the beneficial difference in lipid profile observed in the salmon group, it should be noted that the mean baseline lipid levels in both diet groups were within the normal range or at borderline. According to the Clinical Practice Guideline of Malaysia, a person is 
diagnosed with dyslipidaemia when he/she has a total cholesterol of $>5.2 \mathrm{mmol} / \mathrm{l}$, triglycerides of $>1.7 \mathrm{mmol} / 1$, HDL-cholesterol of $<1.0 \mathrm{mmol} / 1$ (males) or $<1.2 \mathrm{mmol} / 1$ (females), and/or LDL-cholesterol of $<3.0 \mathrm{mmol} / 1$ or $<3.8 \mathrm{mmol} / 1$ (if triglycerides $>4.5 \mathrm{mmol} / \mathrm{l}$ ) [56]. Although the observed improvement in the salmon group may not be clinically meaningful to the study population, it may at least be useful as primary prevention. Moreover, it is possible that other dietary nutrients and physical activity levels could have influenced the results, although both diet groups did not show significant differences in terms of diet quality $[57,58]$. The increasing trend of carbohydrate intake and reducing trend of physical activity level observed in the YSS group after 8 weeks were much greater than the salmon group, though not statistically significant.

In terms of inflammatory markers, current results demonstrated no significant changes with the consumption of YSS. On the contrary, salmon was found to exert a significant suppression effect on the pro-inflammatory marker IL-6 compared with YSS. Serum TNF- $\alpha$ was also decreased significantly in the salmon group after 8 weeks but not significantly in between-group difference. Results of the present study corroborate those reported by Zhang et al. [8] regarding the beneficial effect of 8 -week salmon consumption on lowering and IL- 6 and TNF- $\alpha$ levels. Conversely, a later randomized trial using mixed fish, equivalent to approximately $800 \mathrm{mg} /$ day of EPA+DHA, did not support the beneficial effect of consuming omega-3 rich fish for 8 weeks on serum cytokines levels [44]. It is believed that the dietary EPA+DHA intake in Grieger et al. [59] (800 mg/day) was lower than that in Zhang et al. [8] (1600 mg/day), and the present study (1000 mg/day) to improve the inflammatory markers.

There are several possible explanations for the varied effects of YSS and salmon on health outcomes. First, dietary inclusion of YSS and salmon did not effectively increase serum EPA+DHA despite their similar omega-3 content. When the omega-3 fatty acids were studied individually, higher EPA intake reflected from salmon, which had higher EPA content, increased the serum EPA level of subjects after 8 weeks. There is growing evidence that EPA and DHA exert differential health benefits $[60,61]$. The current findings acknowledge that the observed changes may mainly be associated with dietary intake of EPA. However, research remains inconclusive as to whether EPA or DHA is better to improve outcomes $[60,61]$. Considering the potentially independent effects of EPA or DHA on outcomes would be meaningful in the future. Second, YSS and salmon have different omega-6 to omega-3 fatty acids (n6:n3) ratio. A recent study found that even with similar $\mathrm{EPA}+\mathrm{DHA}$ content, the beneficial effects on lipid profile and inflammatory markers tend to be greater when consumed fish with a lower ratio of omega- 6 to omega- 3 fatty acids (n6:n3 ratio) [62]. If this effect is confirmed, it could explain the significant changes in lipid profile and inflammatory markers observed in the salmon group instead of the YSS group since salmon had a lower n6:n3 ratio than YSS (0.3 vs. 0.2) [19,20]. Taken together, we can speculate that higher dietary EPA intake and lower n6:n3 ratio may be associated with greater beneficial effects on the lipid profile and inflammatory markers. Further studies are necessary to confirm this hypothesis.

As discussed in our previous study [63], the amount of fish given was nearly double the recommended serving size $(150 \mathrm{~g})$ [64], although the intention was to mimic the omega3 intake recommendation (1000 mg/day or $7000 \mathrm{mg} /$ week) [23]. Consuming such an amount of fish is unlikely to be practical in the long term. Harris et al. [65] observed that incorporating EPA+DHA into blood lipids was equally effective when provided an identical amount of EPA+DHA from oily fish on a weekly basis or from fish oil supplementation on a daily basis. However, an in vitro study carried out by Browning et al. [66] reported to have better EPA+DHA status when consuming a moderate amount regularly (daily) instead of a higher amount intermittently (twice per week), despite both administrations providing an identical amount of EPA+DHA per week. A recent in vivo study suggested that having a large dose of omega-3 fatty acids once per week is more effective than a smaller dose delivered daily [67]. Additional research to compare the effectiveness of taking EPA+DHA derived from oily fish consumption on a daily and intermittently basis is warranted. 
To our best knowledge, this is the first randomised crossover study that compared the health benefits of YSS and salmon matched for EPA+DHA content. This study design is one of the most powerful designs for examining the efficacy of dietary treatments [68]. However, there are several limitations that should be addressed in this study. First, the dietary data and the serum EPA+DHA compliance biomarker showed no increase in the YSS period and very little increase in the salmon period, despite a goal of reaching an intake of approximately $1000 \mathrm{mg} /$ day EPA+DHA. The results raise doubts about whether the subjects truly adhered to the study protocol, although subjects reported a good compliance index based on meal photos taken. Poor compliance is not uncommon in randomized trials with free-living subjects. One of the possible reasons for the non-compliance in this study is that the fish was given at nearly twice the recommended serving size, which was not usual. Therefore, subjects may fail to finish the diet treatment. Moreover, YSS is rather small and bony and is commonly prepared by deep-frying. Instead, the fish was steamed to retain most of its nutrients in this study. This little bony fish may cause hassle to the eating process. Moreover, salmon is a favourite fish of people but is also expensive; not all could afford it. It cannot rule out the possibility that subjects may share the diet treatment with family or friends. All these factors may relate to subject's non-compliance in this study $[69,70]$. The primary purpose of self-administered two-day $24 \mathrm{HR}$ was to monitor the compliance with dietary intake. Although the intake of other nutrients was generally not different between groups, we did not specify which two days were to be recorded. This presents a further limitation to the study.

Second, in the earlier work of this study, which reported preliminary findings for the first intervention period [42], the YSS group had higher total cholesterol and HDLcholesterol after 8 weeks [42]. Nevertheless, the modulation of YSS on these outcomes did not last on the second intervention period. A possible explanation is that subjects compliance was compromised due to the duration of intervention and complexity of the diet treatment [69]. At the second intervention phase, subjects in the second group may have less motivation since it was more hassle to consume the bony fish YSS than salmon.

Third, even though there were statistical differences of decreasing IL- 6 and TNF- $\alpha$ after 8 weeks of salmon consumption and between-group difference on IL- 6 concentration, the changes were very small. Therefore, it is difficult to conclude the beneficial effects of salmon on these biomarkers.

Forth, the sample size was calculated based on the effect size of the primary outcome while the variables discussed in this paper were the secondary outcomes. This study had relatively wide confidence intervals that crossed zero for most variables. This may indicate an inadequate sample size and the study may not have adequate power to detect existing differences. We considered that this study would produce possible differences in the study outcomes due to results demonstrated by previous clinical trials of omega-3 rich fish $[8,23,54,55,59]$. Therefore, more extensive human clinical trials with larger sample sizes are necessary.

\section{Conclusions}

We concluded that short-term consumption of YSS and salmon at a dosage equivalent to approximately $1000 \mathrm{mg} /$ day of EPA+DHA did not exert similar effects on lipid profile and inflammatory markers among healthy overweight adults. Salmon with a higher EPA content elicited greater significant health benefits than YSS.

Author Contributions: Conceptualization, A.A. and S.P.L.; methodology, W.L.C. and S.P.L.; formal analysis, W.L.C.; investigation, W.L.C., S.M.N. and I.Z.I.; resources, S.P.L.; writing-original draft preparation, W.L.C.; writing-review and editing, A.A., S.M.N., I.Z.I. and S.P.L.; supervision, A.A., S.M.N., I.Z.I. and S.P.L.; project administration, W.L.C. and S.P.L.; funding acquisition, S.P.L. All authors have read and agreed to the published version of the manuscript.

Funding: This work was supported by the Ministry of Science, Technology and Innovation Malaysia (eSciencefund, grant number 5450811) and Universiti Putra Malaysia (Putra Graduate Initiative 
Grant, grant number GP-IPS/2018/9612300). The funders had no role in the design, analysis or writing of this article.

Institutional Review Board Statement: The study was conducted according to the guidelines of the Declaration of Helsinki, and approved by the Ethics Committee of Universiti Putra Malaysia (protocol code YSS002 and 11 July 2016).

Informed Consent Statement: Informed consent was obtained from all subjects involved in the study.

Data Availability Statement: The data presented in this study are available on request from the first or corresponding author.

Acknowledgments: The authors wish to thank all the staff and subjects for their support and cooperation in this study.

Conflicts of Interest: The authors declare no conflict of interest.

\section{References}

1. Malaysians Eat More Fish than Japanese, Reveals Study. Available online: https://www.thestar.com.my/news/nation/2014/06/ 19/malaysians-eat-more-fish-than-japanese-reveals-study (accessed on 30 August 2019).

2. Ahmad, N.I.; Wan Mahiyuddin, W.R.; Tengku Mohamad, T.R.; Ling, C.Y.; Daud, S.F.; Hussein, N.C.; Abdullah, N.A.; Shaharudin, R.; Sulaiman, L.H. Fish consumption pattern among adults of different ethnics in Peninsular Malaysia. Food Nutr. Res. 2016, 60, 32697. [CrossRef]

3. Gammelmark, A.; Nielsen, M.S.; Bork, C.S.; Lundbye-Christensen, S.; Tjønneland, A.; Overvad, K.; Schmidt, E.B. Association of fish consumption and dietary intake of marine n-3 PUFA with myocardial infarction in a prospective Danish cohort study. Br. J. Nutr. 2016, 116, 167-177. [CrossRef]

4. Grung, B.; Hansen, A.L.; Berg, M.; Møen-Knudseth, M.P.; Olson, G.; Thornton, D.; Dahl, L.; Thayer, J.F. Exploratory multivariate analysis of the effect of fatty fish consumption and medicinal use on heart rate and heart rate variability data. Front. Psychol. 2015, 6, 135. [CrossRef]

5. Kim, H.; Park, S.; Yang, H.; Choi, Y.J.; Huh, K.B.; Chang, N. Association between fish and shellfish, and omega-3 PUFAs intake and CVD risk factors in middle-aged female patients with type 2 diabetes. Nutr. Res. Pract. 2015, 9, 496-502. [CrossRef]

6. Rhee, J.J.; Kim, E.; Buring, J.E.; Kurth, T. Fish consumption, omega-3 fatty acids, and risk of cardiovascular disease. Am. J. Prev. Med. 2017, 52, 10-19. [CrossRef]

7. Kastelein, J.J.P.; Maki, K.C.; Susekov, A.; Ezhov, M.; Nordestgaard, B.G.; Machielse, B.N.; Kling, D.; Davidson, M.H. Omega-3 free fatty acids for the treatment of severe hypertriglyceridemia: The EpanoVa for lowering very high triglyceridEs (EVOLVE) trial. $J$. Clin. Lipidol. 2014, 8, 94-106. [CrossRef]

8. Zhang, J.; Wang, C.; Li, L.; Man, Q.; Meng, L.; Song, P.; Frøyland, L.; Du, Z.Y. Dietary inclusion of salmon, herring and pompano as oily fish reduces CVD risk markers in dyslipidaemic middle-aged and elderly Chinese women. Br. J. Nutr. 2012, 108, 1455-1465. [CrossRef]

9. Wang, H.; Daggy, B.P. The role of fish oil in inflammatory eye diseases. Biomed. Hub 2017, 2, 6. [CrossRef]

10. Alhassan, A.; Young, J.; Lean, M.E.; Lara, J. Consumption of fish and vascular risk factors: A systematic review and meta-analysis of intervention studies. Atherosclerosis 2017, 266, 87-94. [CrossRef]

11. Clarke, S.D. Polyunsaturated fatty acid regulation of gene transcription: A molecular mechanism to improve the metabolic syndrome. J. Nutr. 2001, 131, 1129-1132. [CrossRef]

12. Faeh, D.; Minehira, K.; Schwarz, J.M.; Periasamy, R.; Park, S.; Tappy, L. Effect of fructose overfeeding and fish oil administration on hepatic de novo lipogenesis and insulin sensitivity in healthy men. Diabetes 2005, 54, 1907-1913. [CrossRef]

13. Jump, D.B. Fatty acid regulation of hepatic lipid metabolism. Curr. Opin. Clin. Nutr. Metab. Care 2011, 14, 115. [CrossRef]

14. Calder, P.C. Omega-3 fatty acids and inflammatory processes: From molecules to man. Biochem. Soc. Trans. 2017, 45, 1105-1115. [CrossRef]

15. Gropper, S.S.; Smith, J.L. Advanced Nutrition and Human Metabolism, 7th ed.; Cengage Learning: Boston, MA, USA, 2017; pp. 126-171.

16. Nettleton, J.A. Omega-3 Fatty Acids and Health; Springer Science and Business Media: Berlin, Germany, $2012 ;$ pp. 1-45.

17. United States Department of Agriculture (USDA). National Nutrient Database for Standard Reference. Available online: https: / / fdc.nal.usda.gov /index.html (accessed on 25 May 2017).

18. Trout Proud. Available online: https://www.pressreader.com/malaysia/the-star-malaysia-star2/20160605/282127815738258 (accessed on 5 June 2016).

19. Blanchet, C.; Lucas, M.; Julien, P.; Morin, R.; Gingras, S.; Dewailly, E. Fatty acid composition of wild and farmed Atlantic salmon (Salmo salar) and rainbow trout (Oncorhynchus mykiss). Lipids 2005, 40, 529-531. [CrossRef]

20. Abd Aziz, N.; Azlan, A.; Ismail, A.; Mohd Alinafiah, S.; Razman, M.R. Quantitative determination of fatty acids in marine fish and shellfish from warm water of Straits of Malacca for nutraceutical purposes. BioMed Res. Int. 2013, 2013, 284329. [CrossRef] 
21. Abdulrahman, Y.; Azlan, A.; Peng, L.S.; Ismail, I.Z.; Noor, S.M. Effects of EPA + DHA from yellow-stripe scad and salmon on platelet and endothelial cell-related cytokines of healthy overweight Malaysians. Life Sci. Med. Biomed. 2019, 3, 28.

22. WHO Expert Consultation. Appropriate body-mass index for Asian populations and its implications for policy and intervention strategies. Lancet 2004, 363, 157-163. [CrossRef]

23. Patterson, A.C.; Chalil, A.; Henao, J.J.A.; Streit, I.T.; Stark, K.D. Omega-3 polyunsaturated fatty acid blood biomarkers increase linearly in men and women after tightly controlled intakes of $0.25,0.5$, and $1 \mathrm{~g} / \mathrm{d}$ of EPA + DHA. Nutr. Res. 2015, 35, 1040-1051. [CrossRef]

24. Reiner, Z.; Catapano, A.L.; De Backer, G.; Graham, I.; Taskinen, M.R.; Wiklund, O.; Agewall, S.; Alegria, E.; Chapman, M.J.; Durrington, P.; et al. ESC/EAS guidelines for the management of dyslipidaemias: The task force for the management of dyslipidaemias of the European Society of Cardiology (ESC) and the European Atherosclerosis Society (EAS). Eur. Heart J. 2011, 32, 1769-1818.

25. Koubaa, A.; Mihoubi, N.B.; Abdelmouleh, A.; Bouain, A. Comparison of the effects of four cooking methods on fatty acid profiles and nutritional composition of red mullet (Mullus barbatus) muscle. Food Sci. Biotechnol. 2012, 21, 1243-1250. [CrossRef]

26. Choo, P.Y. Retention of EPA and DHA In Selected Fish Using Different Cooking Methods Compared to Salmon. Bachelor's Thesis, Universiti Putra Malaysia, Seri Kembangan, Malaysia, 2015.

27. Karanicolas, P.J.; Farrokhyar, F.; Bhandari, M. Blinding: Who, what, when, why, how? Can. J. Surg. 2010, 53, 345.

28. Ministry of Health Malaysia. Malaysian Dietary Guidelines; National Coordinating Committee on Food and Nutrition: Putrajaya, Malaysia, 2010; pp. 1-16.

29. Cao, J.; Schwichtenberg, K.A.; Hanson, N.Q.; Tsai, M.Y. Incorporation and clearance of omega-3 fatty acids in erythrocyte membranes and plasma phospholipids. Clin. Chem. 2006, 52, 2265-2272. [CrossRef] [PubMed]

30. Singal, A.G.; Higgins, P.D.R.; Waljee, A.K. A primer on effectiveness and efficacy trials. Clin. Transl. Gastroenterol. 2014, 5, e45. [CrossRef] [PubMed]

31. Dahl Lassen, A.; Poulsen, S.; Ernst, L.; Kaae Andersen, K.; Biltoft-Jensen, A.; Tetens, I. Evaluation of a digital method to assess evening meal intake in a free-living adult population. Food Nutr. Res. 2010, 54, 5311. [CrossRef] [PubMed]

32. Wandless, I.; Mucklow, J.C.; Smith, A.; Prudham, D. Compliance with prescribed medicines: A study of elderly patients in the community. J. R. Coll. Gen. Pract. 1979, 29, 391-396.

33. Beer-Borst, S.; Amado, R. Validation of a self-administered 24-hour recall questionnaire used in a large-scale dietary survey. Eur. J. Nutr. 1995, 34, 183-189. [CrossRef]

34. Craig, C.L.; Marshall, A.L.; Sjostrom, M.; Bauman, A.E.; Booth, M.L.; Ainsworth, B.E.; Pratt, M.; Ekelund, U.; Yngve, A.; Sallis, J.F.; et al. International physical activity questionnaire: 12-country reliability and validity. Med. Sci. Sports Exerc. 2003, 35, 1381-1395. [CrossRef]

35. Harris, W.S.; Pottala, J.V.; Vasan, R.S.; Larson, M.G.; Robins, S.J. Changes in erythrocyte membrane trans and marine fatty acids between 1999 and 2006 in older Americans. J. Nutr. 2012, 142, 1297-1303. [CrossRef]

36. Morrison, W.R.; Smith, L.M. Preparation of fatty acid methyl esters and dimethylacetals from lipids with boron fluoride-methanol. J. Lipid Res. 1964, 5, 600-608. [CrossRef]

37. David, F.; Sandra, P.; Vickers, A.K. Column selection for the analysis of fatty acid methyl esters. Food Anal. Appl. $2005,19,19$.

38. Friedewald, W.T.; Levy, R.I.; Fredrickson, D.S. Estimation of the concentration of low-density lipoprotein cholesterol in plasma, without use of the preparative ultracentrifuge. Clin. Chem. 1972, 18, 499-502. [CrossRef] [PubMed]

39. Dobiášová, M.; Frohlich, J. The plasma parameter log (TG/HDL-C) as an atherogenic index: Correlation with lipoprotein particle size and esterification rate inapob-lipoprotein-depleted plasma (FERHDL). Clin. Biochem. 2001, 34, 583-588. [CrossRef]

40. Machin, D.; Campbell, M.J.; Tan, S.B.; Tan, S.H. Sample Size Tables for Clinical Studies, 3rd ed.; John Wiley \& Sons: Hoboken, NJ USA, 2009; pp. 58-66.

41. Phang, M.; Lincz, L.F.; Garg, M.L. Eicosapentaenoic and docosahexaenoic acid supplementations reduce platelet aggregation and hemostatic markers differentially in men and women. J. Nutr. 2013, 143, 457-463. [CrossRef] [PubMed]

42. Vickers, A.J. Analysis of variance is easily misapplied in the analysis of randomized trials: A critique and discussion of alternative statistical approaches. Psychosom. Med. 2005, 67, 652-655. [CrossRef] [PubMed]

43. Fergusson, D.; Aaron, S.D.; Guyatt, G.; Hébert, P. Post-randomisation exclusions: The intention to treat principle and excluding patients from analysis. Br. Med. J. 2002, 325, 652-654. [CrossRef]

44. Maclure, M. The case-crossover design: A method for studying transient effects on the risk of acute events. Am. J. Epidemiol. 1991, 133, 144-153. [CrossRef]

45. Cleophas, T.J.M.; De Vogel, E.M. Crossover studies are a better format for comparing equivalent treatments than parallel-group studies. Pharm. World Sci. 1998, 20, 113-117. [CrossRef]

46. Richens, A. Proof of efficacy trials: Cross-over versus parallel-group. Epilepsy Res. 2001, 45, 43-47. [CrossRef]

47. Browning, L.M.; Walker, C.G.; Mander, A.P.; West, A.L.; Madden, J.; Gambell, J.M.; Young, S.; Wang, L.; Jebb, S.A.; Calder, P.C. Incorporation of eicosapentaenoic and docosahexaenoic acids into lipid pools when given as supplements providing doses equivalent to typical intakes of oily fish. Am. J. Clin. Nutr. 2012, 96, 748-758. [CrossRef]

48. Rundblad, A.; Holven, K.B.; Bruheim, I.; Myhrstad, M.C.; Ulven, S.M. Effects of fish and krill oil on gene expression in peripheral blood mononuclear cells and circulating markers of inflammation: A randomised controlled trial. J. Nutr. Sci. 2018, 7, e10. [CrossRef] 
49. Lindqvist, H.M.; Langkilde, A.M.; Undeland, I.; Sandberg, A.S. Herring (Clupea harengus) intake influences lipoproteins but not inflammatory and oxidation markers in overweight men. Br. J. Nutr. 2009, 101, 383-390. [CrossRef]

50. Sami Khaza, M. Atherogenic Index of Plasma (AIP) as a parameter in predicting cardiovascular risk in males compared to the conventional dyslipidemic indices (cholesterol ratios). Kerbala J. Med. 2013, 6, 1506-1513.

51. Derosa, G.; Cicero, A.F.; D'Angelo, A.; Borghi, C.; Maffioli, P. Effects of n-3 PUFAs on fasting plasma glucose and insulin resistance in patients with impaired fasting glucose or impaired glucose tolerance. Biofactors 2016, 42, 316-322.

52. Zibaeenezhad, M.J.; Ghavipisheh, M.; Attar, A.; Aslani, A. Comparison of the effect of omega-3 supplements and fresh fish on lipid profile: A randomized, open-labeled trial. Nutr. Diabetes 2017, 7, 1. [CrossRef] [PubMed]

53. Devadawson, C.; Jayasinghe, C.; Sivakanesan, R.; Arulnithy, K. Assessment of lipid profile and atherogenic indices for cardiovascular disease risk based on different fish consumption habits. Assessment 2016, 9, 156-160.

54. Gordon, D.J.; Knoke, J.; Probstfield, J.L.; Superko, R.; Tyroler, H.A. High-density lipoprotein cholesterol and coronary heart disease in hypercholesterolemic men: The lipid research clinics coronary primary prevention trial. Circulation 1986, 74, 1217-1225. [CrossRef]

55. Vazquez, C.; Botella-Carretero, J.I.; Corella, D.; Fiol, M.; Lage, M.; Lurbe, E.; Richart, C.; Fernández-Real, J.M.; Fuentes, F.; Ordóñez, A.; et al. White fish reduces cardiovascular risk factors in patients with metabolic syndrome: The WISH-CARE study, a multicenter randomized clinical trial. Nutr. Metab. Cardiovasc. Dis. 2014, 24, 328-335. [CrossRef] [PubMed]

56. 5th Edition of Clinical Practice Guidelines: Management of Dyslipidaemia 2017. Available online: https://www.moh.gov.my/ moh/resources/Penerbitan/CPG/CARDIOVASCULAR/4.pdf (accessed on 11 September 2018).

57. Pinart, M.; Jeran, S.; Boeing, H.; Stelmach-Mardas, M.; Standl, M.; Schulz, H.; Harris, C.; von Berg, A.; Herberth, G.; Koletzko, S.; et al. Dietary macronutrient composition in relation to circulating HDL and non-HDL cholesterol: A federated individual-level analysis of cross-sectional data from adolescents and adults in 8 European studies. J. Nutr. 2021, 151, 2317-2329. [CrossRef] [PubMed]

58. El Bilbeisi, A.H.; Hosseini, S.; Djafarian, K. The association between physical activity and the metabolic syndrome among type 2 diabetes patients in Gaza strip, Palestine. Ethiop. J. Health Sci. 2017, 27, 273-282. [CrossRef] [PubMed]

59. Grieger, J.A.; Miller, M.D.; Cobiac, L. Investigation of the effects of a high fish diet on inflammatory cytokines, blood pressure, and lipids in healthy older Australians. Food Nutr. Res. 2014, 58, 20369. [CrossRef]

60. Innes, J.K.; Calder, P.C. The differential effects of eicosapentaenoic acid and docosahexaenoic acid on cardiometabolic risk factors: A systematic review. Int. J. Mol. Sci. 2018, 19, 532. [CrossRef]

61. Yanai, H.; Masui, Y.; Katsuyama, H.; Adachi, H.; Kawaguchi, A.; Hakoshima, M.; Waragai, Y.; Harigae, T.; Sako, A. An improvement of cardiovascular risk factors by omega-3 polyunsaturated fatty acids. J. Clin. Med. Res. 2018, 10, 281-289. [CrossRef]

62. Sofi, F.; Giorgi, G.; Cesari, F.; Gori, A.M.; Mannini, L.; Parisi, G.; Casini, A.; Abbate, R.; Gensini, G.F.; Poli, B.M. The atherosclerotic risk profile is affected differently by fish flesh with a similar EPA and DHA content but different n-6/n-3 ratio. Asia Pac. J. Clin Nutr. 2013, 22, 32-40.

63. Chang, W.L.; Azrina, A.; Sabariah, M.N.; Ismail, I.Z.; Loh, S.P. Effects of consuming yellowstripe scad versus salmon on lipid profile, fasting glucose, body weight status and blood pressure among healthy overweight Malaysian adults. Malays. J. Nutr. 2017, 23, 343-352.

64. Fish, Fish Oils, n-3 Polyunsaturated Fatty Acids and Cardiovascular Health. Heart Foundation Position Statement 2008. Available online: https://www.heartfoundation.org.au/getmedia/5195fde5-87f6-4c2a-b7c3-0745a47e5ab7/Summary_Evidence_FISH_ FISH-OILS_FINAL.pdf (accessed on 8 July 2019).

65. Harris, W.S.; Pottala, J.V.; Sands, S.A.; Jones, P.G. Comparison of the effects of fish and fish-oil capsules on the n-3 fatty acid content of blood cells and plasma phospholipids. Am. J. Clin. Nutr. 2007, 86, 1621-1625. [CrossRef]

66. Browning, L.M.; Walker, C.G.; Mander, A.P.; West, A.L.; Gambell, J.; Madden, J.; Calder, P.C.; Jebb, S.A. Compared with daily, weekly n-3 PUFA intake affects the incorporation of eicosapentaenoic acid and docosahexaenoic acid into platelets and mononuclear cells in humans. J. Nutr. 2014, 144, 667-672. [CrossRef]

67. Ghasemifard, S.; Sinclair, A.J.; Kaur, G.; Lewandowski, P.; Turchini, G.M. What is the most effective way of increasing the bioavailability of dietary long chain omega-3 fatty acids-Daily vs. weekly administration of fish oil? Nutrients 2015, 7, 5241. [CrossRef]

68. Mehrotra, D.V. A recommended analysis for $2 \times 2$ crossover trials with baseline measurements. Pharm. Stat. 2014, 13, 376-387. [CrossRef]

69. Jin, J.; Sklar, G.E.; Oh, V.M.S.; Chuen Li, S. Factors affecting therapeutic compliance: A review from the patient's perspective. Ther. Clin. Risk Manag. 2008, 4, 269.

70. Mohd Suan, M.A.; Asli, S.E.; Abdullah, W.M.; Shafie, Z.; Johari, N.H. Patient perspective on factors contributing to nonadherence to dietary therapy: A qualitative study in multicultural population of Kedah, Malaysia. Int. Q. Community Health Educ. 2019, 39, 217-223. [CrossRef] 